\title{
Modeling the creep damage effect on the creep crack growth behavior of rotor steel
}

https://doi.org/10.1515/phys-2018-0068

Received April 25, 2018; accepted May 29, 2018

\begin{abstract}
To evaluate the fracture life of steam turbine HPIP rotors more accurately, an understanding of the creep damage effect on creep cracking performance of serviceexposed rotor steel, and a proper creep crack growth (CCG) model considering the creep damage effect, is essential. In the present work comparative CCG tests were carried out on virgin and rotor steel that had been in service for 16 years, to examine the differences in creep crack microstructure and CCG rate between these two specimen types. Test results showed that the CCG rate of serviceexposed steel is accelerated by creep damage due to metallurgical deterioration. Based on the CCG model derived by Webster, an improved CCG model is proposed by replacing the constant exponent with a creep-damage-related variable. To validate the improved model, a comparison of $\mathrm{da} / \mathrm{dt}$ vs. $\mathrm{C}^{\star}$ between experiment data and the CCG models was conducted. The predictive result of the improved model is in better agreement with the experiment results than the classical CCG and Webster models for the serviceexposed rotor steel. With decrement of $C^{\star}$ value within the improved CCG model, the remaining life of HP-IP rotors may be predicted more accurately.
\end{abstract}

Keywords: creep crack growth, creep damage, Cr-Mo-V steel, high temperature fracture

PACS: 46.50.+a, 62.20.mt

\footnotetext{
Ting Ye: Key Laboratory of Pressurized System and Safety, Ministry of Education, East China University of Science and Technology, Shanghai 200237, China, E-mail: yeziting12@126.com *Corresponding Author: Zhengdong Wang: Key Laboratory of Pressurized System and Safety, Ministry of Education, East China University of Science and Technology, Shanghai 200237, China, E-mail: zdwang@ecust.edu.cn

Fu-Zhen Xuan: Key Laboratory of Pressurized System and Safety, Ministry of Education, East China University of Science and Technology, Shanghai 200237, China, E-mail: fzxuan@ecust.edu.cn
}

\section{Introduction}

Cr-Mo-V rotor steel was widely used for steam turbine HPIP rotors in the early nineties in China [1]. Under high-tomedium stresses, these rotors are subjected to temperatures up to $538^{\circ} \mathrm{C}$ for several decades. According to the characterisation research of Cr-Mo-V rotor steel [2], creep is a concern in the operating temperature range of steam turbines. Elevated temperatures and the stress concentration will lead to creep crack growth, thus the creep crack is likely to occur at the geometric discontinuity of rotors, and endangers the safety of plants in service. Most of the rotors have worked for over 15 years. The remaining CCG life is crucial to the safety operation of these power plants.

Long service times under creep conditions will produce creep damage in steel. Creep damage evolution is considered to involve structure change processes such as decomposition of pearlite/bainite, development of the carbide precipitation, and appearance of voids/cavities along grain boundaries. Structural changes cause mechanical properties, such as strength, toughness etc., to be quite different from those of unused material. The difference in creep cracking properties between unused and serviceexposed steel has rarely been reported. Due to the importance of CCG on residual life evaluation of HP-IP rotors, an accurate CCG rate prediction model is needed.

$C^{\star}$ is one of the most commonly utilized high temperature fracture mechanics parameters along with the stress intensity factor $K$, net section stress $\sigma_{n}, Q^{\star}$ parameter etc. $[3,4] . C^{\star}$ has been validated to relate well to steady CCG rates, and it has a sound theoretical basis that was developed from plastic fracture mechanics. The integral expression for $C^{\star}$ is shown in equation (1).

$$
C^{\star}=\int_{\Gamma} W_{s}^{\star} d y-T_{i} \frac{\partial \dot{u}_{i}}{\partial x} d s
$$

where $W_{s}^{\star}$ is the creep strain energy rate density, $T_{i}$ and $\dot{u}_{i}$ are components of the traction and creep displacement rate vectors, $x$ and $y$ are the coordinates along and perpendicular to the crack tip, and $s$ is the arc length along $\Gamma$ path. 
$W_{s}^{\star}$ is given by Eq. (2).

$$
W_{s}^{\star}=\int \sigma_{i j} d \dot{\varepsilon}_{i j}
$$

$\sigma_{i j}$ is stress tensor and $\dot{\varepsilon}_{i j}$ is the creep strain rate tensor.

The correlations of steady-state creep crack growth rate $\mathrm{d} a / \mathrm{d} t$ with $C^{\star}$ can be represented by straight lines of different slopes on $\log / \log$ plots and expressed by power laws, such as

$$
\dot{a}=M_{0} C^{\star} \Phi_{0}
$$

where $M_{0}$ and $\Phi_{0}$ are material constants. $M_{0}$ and $\Phi_{0}$ in equation (3) are defined as follows:

$$
\begin{gathered}
M_{0}=\left(\frac{n+1}{n+1-v}\right) \frac{t_{r}}{t_{r}^{\star}}\left(\frac{1}{I_{n} C_{A} r_{c}}\right)^{v /(n+1)} \frac{r_{c}}{B_{r}} \\
\phi_{0}=\frac{n}{n+1}
\end{gathered}
$$

Eq. (3), hereafter the classical CCG model, is widely used in the CCG life evaluation of high-temperature components without considering the creep damage influence. Based on the $C^{\star}$ parameter, some researchers $[5,6]$ introduced creep damage into the creep crack propagation problem. For example, Webster etc. [7] proposed a model by considering creep damage that accumulates in a creep process zone ahead of the crack tip; the creep damage is represented by creep ductility, and the crack extends when the creep ductility of material at the crack tip is exhausted. Murakami [8] has conducted experiments on plates with machined holes to approximate the net section loss occurring in creep cavitation or wedge cracking processes, and a creep damage model is developed by coupling creep deformation with a damage factor on the basis of conventional Kachanov-Rabotnov creep damage theory [9]. Creep damage in these CCG studies is always considered as the formation, growth and coalescence of micro-cavities that occur in front of the extending creep cracks, and these CCG models were found to exactly describe the cracking phenomenon in the last stage of the CCG procedure. However, the current CCG models are not adequate to evaluate the creep cracking life of in-service rotors, because thermal aging damage to the steel, produced through long-term exposure to creep conditions, will lead to mechanical property changes. These changes affect some material constants; for example creep exponent $n$ changes as a function of the creep damage $\omega$. Since $C^{\star}$ is characterized by the creep exponent $n$, the parameters $\Phi_{0}$ of service-exposed and virgin steel are different according to Eq. (5). In order to avoid premature failure of HP-IP rotors, a more precise CCG model should be established, through reflecting the mechanical properties changes by relating the parameters with a creep damage factor.
In this work, creep cracking experiments are carried out on the service-exposed and virgin rotor steel. Test results are compared to investigate the differences in creep cracking performance due to creep damage impacts. An improved CCG model is then proposed. The proposed model is based on the CCG model advised by Webster [10]. Webster's CCG model is particularly interesting because it coupled the creep damage with the CCG behavior, and the predicted result accords with observations more closely. Because the CCG performance parameters will be changed according to the change of the creep performance parameter, Webster's CCG model will be improved by altering parameters to embody the creep damage effect.

\section{Creep crack growth test of service-exposed rotor steel}

\subsection{Creep crack growth test}

A low-alloy steel with Chinese brand name 30Cr1Mo1V is investigated in this paper. The CCG experiments were carried out on virgin and service-exposed steel based on ASTM standard E1457-07 [11]. The service-exposed material investigated in the present research was taken from a turbine HP-IP rotor which has been in service at $538^{\circ} \mathrm{C}$ for 140000 hours. All the specimens were machined into CT pre-cracked specimens for CCG tests. The specimens were $10 \mathrm{~mm}$ width, and a pre-crack of $10 \mathrm{~mm}$ length was introduced by electrical discharge machining (EDM). CCG experiments are conducted in air at $538^{\circ} \mathrm{C}$ with constant force. The crack length was translated from a measured PD ratio. After the experiment, specimens were sectioned along the symmetry plane at mid-thickness. One half was then ground, polished and etched to prepare metallographic specimens. The damage morphology of the service-exposed steel was then observed. Microscopic damage evolution ahead of the creep crack tip caused during CCG procedure was also examined.

\subsection{Test result}

\subsubsection{Comparison of microscopic damage ahead of creep crack tip}

The virgin and service-exposed specimens were tested at the same time, under constant forces of $6 \mathrm{kN}$ and $4 \mathrm{kN}$ for comparison. Microscopic damage in the front of the notch roots for these two specimens was examined using scan- 
ning electron microscopy (SEM). The compared morphology is shown in Figures 1 and 2.

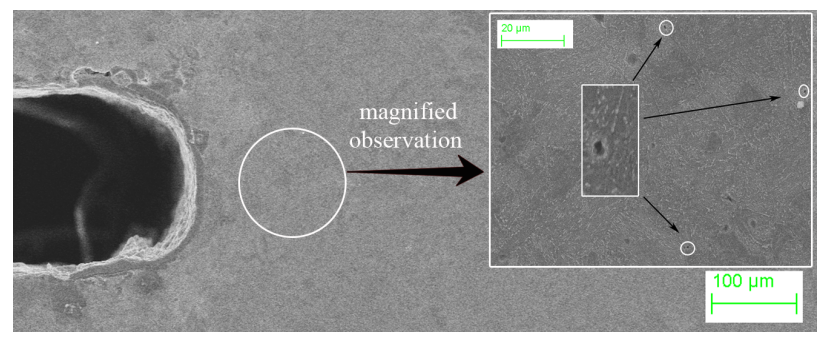

(a)

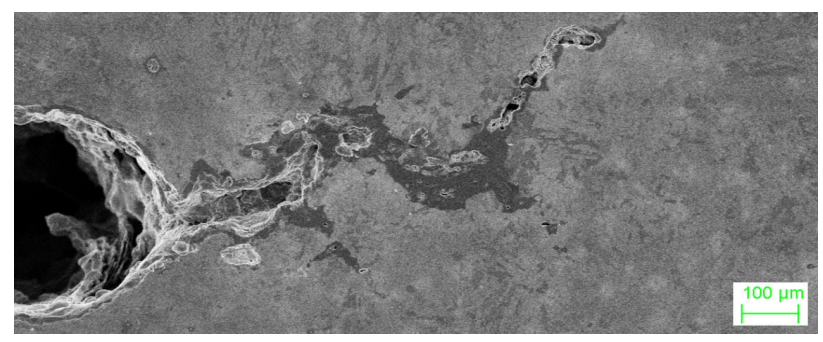

(b)

Figure 1: Microstructure of creep crack ahead the notch root after 120 hours creep crack growth under constant loading $\mathrm{P}=6 \mathrm{kN}$ for (a) virgin steel ; (b) service-exposed steel

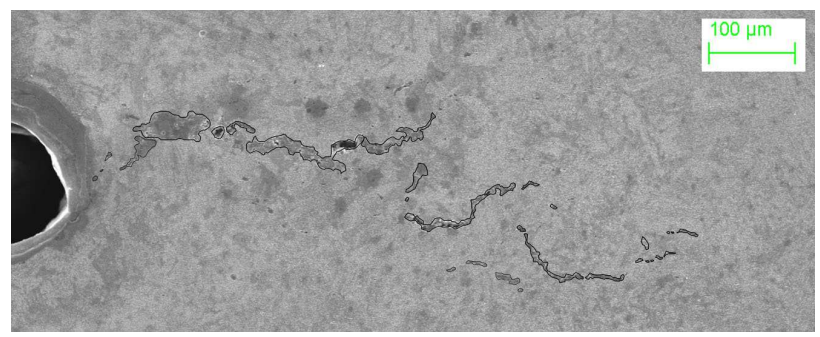

Figure 2: Microstructure of creep crack ahead the notch root after 1500 hours creep crack growth under constant loading $P=4 \mathrm{kN}$ for service-exposed steel

The creep cracking manner is stress dependent. In the present CCG experiments, the creep crack propagation was dominated by the nucleation and coalescence of cavities, which may then lead to intergranular fracture. As observed in Figures 1(b) and 2, two creep crack formation types [12] were distinguished in the CCG experiments: (1) Voids on grain boundaries or wedge crevices at the junction of two, three or four grains. They appear and grow perpendicular to the axis of tensile loading due to grain boundary slip. (2) Larger cavities that formed by the separation of coarser sub-grain structures with the steel matrix. A stress concen- tration was generated at the interface between the inclusions and the steel matrix because of the incompatibility in the mechanical behavior that inducing cracking at the interface between inclusion and matrix. Both these two types of creep crack formation are common and appear simultaneously in high-temperature components. These voids/cavities will grow and coalesce to form micro-cracks and link with the main creep crack with an increase of deformation and creep time. The procedure is then repeated until the creep crack reaches a critical length.

The 30Cr1Mo1V steel specimens with and without creep damage exhibited different creep crack lengths under the same test conditions. After 120 hours of CCG experiment, the virgin specimen remained uncracked and only a few discrete voids, possibly resulting from fabrication, were observed. Unlike the virgin material, for the service-exposed steel a creep crack of $720 \mu$ m length appeared in the front of the notch root, and a set of continuous voids or cavities ahead of the crack tip provided the path for creep crack propagation in the next moment. Comparative CCG tests were conducted under $4 \mathrm{kN}$ loading condition for $1500 \mathrm{~h}$ to imitate a low-loading condition of HP-IP rotor in actual operation. Virgin steel had still not been cracked at this time and its micrograph may refer to Figure 1(a). As shown in Figure 2, the creep crack length of service-exposed steel, however, reached about $300 \mu \mathrm{m}$. Creep crack nucleates about $180 \mu \mathrm{m}$ ahead of the notch, instead of at the notch root, because the notch is a blunt tip of the arc that does not conform to the sharpcrack tip requirement. Under sufficient small loading conditions, the creep crack would extend through the ligament region with negligible grain deformation, and finally lead to fracture of the rotor without visible signs. This difference in creep cracking morphology implies that the CCG rate is promoted by the creep damage.

\subsubsection{Comparison of CCG rate}

The effect of creep damage produced on CCG rate during long-term service was also revealed. The specimens compared in this section were subjected to constant loads of $5 \mathrm{kN}$ and $7.5 \mathrm{kN}$. The comparison of CCG rates is shown in Figure 3. Since the whole CCG fracture time is too long when the loading condition is below $5 \mathrm{kN}$, the residual CCG life can be deduced from the steady creep cracking rate. The tests, using a constant load of $5 \mathrm{kN}$, were interrupted in order to use the test devices effectively.

Figure 3 shows that virgin steel had a longer CCG life than service-exposed steel, under all loading conditions, due to creep damage. Under constant load of $7.5 \mathrm{kN}$, the vir- 


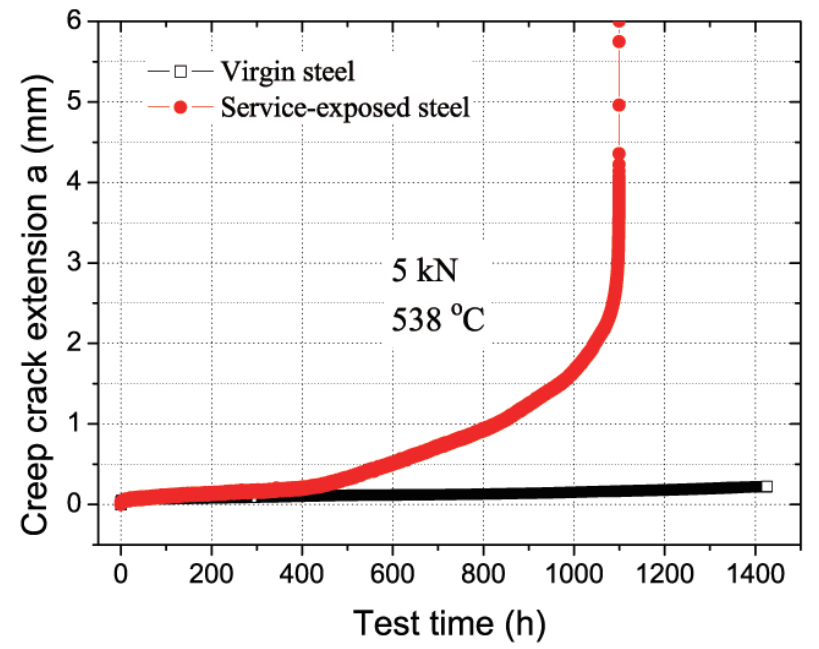

(a)

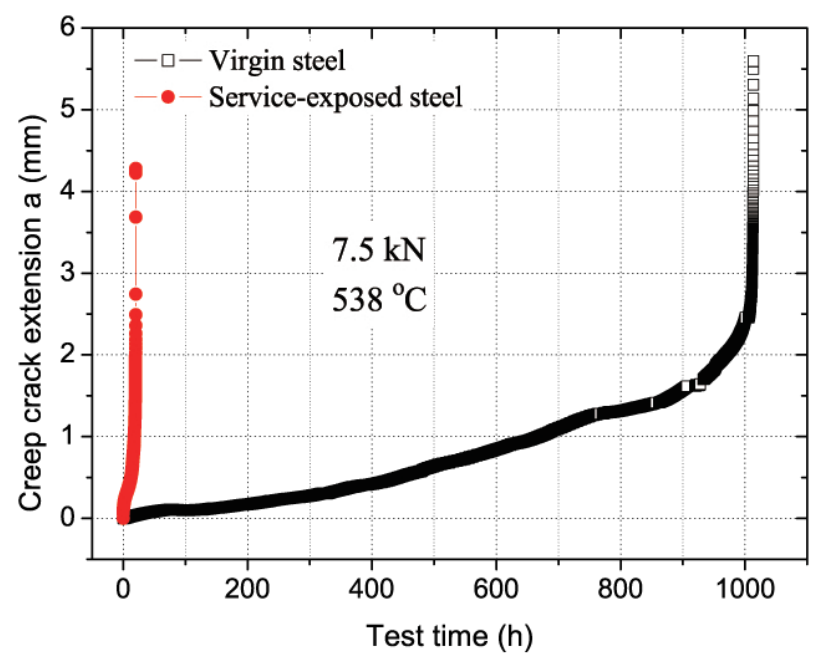

(b)

Figure 3: Creep crack length vs time of virgin and service-exposed 30Cr1Mo1V steel under constant loading condition: (a) $\mathrm{P}=5 \mathrm{kN}$; (b) $\mathrm{P}=7.5 \mathrm{kN}$

gin specimen had a CCG life about 1013 hours, but the lifetime dropped to 20 hours for service-exposed steel. Under the $5 \mathrm{kN}$ loading condition, the fracture life of the serviceexposed specimen can be deduced to be scores of times shorter than the virgin specimen, based on the secondary CCG rate in Figure 3(b). And the difference in CCG lifetimes between virgin and service-exposed steel could increase continuously as the service period of the rotor extends. Referring to similar studies carried out on 2.25Cr1Mo steel that had been in service at $530^{\circ} \mathrm{C}$ for $110000 \mathrm{~h}$, the CCG rate was faster by a factor of $3.1 \mathrm{in}$ the service-exposed steel; this finding is consistent with our test result. In addition, Figure 3 also shows a decrement in final creep crack length for service-exposed steel under the same test condition. Shorter creep crack length is related to faster CCG rate, because a faster CCG rate means higher driving force, which can enhance the stress concentration at the crack tip. The cracking behavior in the remaining ligament area is accelerated, and ductile fracture eventually occurs. It was found that the CCG resistance of the studied serviceexposed $\mathrm{Cr}-\mathrm{Mo}-\mathrm{V}$ steel decreased more than $50 \%$ compared to the virgin steel.

\subsubsection{Discussion of CCG test results}

This paper's studies are part of a project named "Anatomy study of the steam turbine HP/IP/LP rotors". This project is led by the Shanghai Municipal Science and Technology Bureau, participated by some research institutes. Different institutes are responsible for each different subject. The research results were collected and exchanged among these institutes finally. Shanghai Jiao Tong University (SJTU) provided the microstructure features of serviceexposed rotor steel in this project.

All the structural changes, including decomposition of pearlite/bainite, development of the carbides precipitation and appearance of voids/cavities along grain boundaries, may lead to decrement of CCG resistance. For the studied service-exposed steel in this paper, no apparent voids and cracks were observed. The microscopic observation and analysis of specimens offered by SJTU indicate that $\mathrm{M}_{23} \mathrm{C}_{6} / \mathrm{M}_{3} \mathrm{C} / \mathrm{M}_{2} \mathrm{C}$ types of carbides precipitate in the ferrite matrix during high temperature service, which is similar to the thermal aging process. This proves that carbide precipitation is the major cause of CCG resistance decrement of the studied steel. Consulting research $[13,14]$ into thermal aging steel, it is found that service exposure at elevated temperatures results in coarsening and spheroidization of carbides, an increase in inter-particle spacing, and precipitation of more stable carbides in the $\mathrm{Cr}-\mathrm{Mo}-\mathrm{V}$ steel. All these variations mean that the initial microstructure before a CCG test and the microstructure evolution during the CCG period are quite different from the microstructures of the virgin steel. The explanation of how the microstructural changes accelerate CCG rate can relate to the creep property deterioration process described in the literature [15-17]. The fine precipitated $\mathrm{M}_{23} \mathrm{C}_{6}$ carbides, and subsequent coarsening, produces a precipitation-free zone near grain boundaries, which promotes localized creep deformation in the vicinity of those grain boundaries. In reference [13], the coarsening and precipitation of $\mathrm{M}_{2} \mathrm{C}$ carbides depletes $\mathrm{Mo}$ and $\mathrm{C}$ from solid solution. Dissolution of strengthening precipitates causes 
softening of subgrain interiors, particularly in the vicinity of the boundaries (short diffusion paths). This may localize deformation near those subgrain boundaries and cause localized subgrain coarsening, adding to the softening. This process leads to higher stress concentrations at the boundaries which, in connection with higher densities of incoherent precipitates, act as nuclei for pores and tends to enhance intergranular fracture.

With accumulated creep damage caused by metallographic degradation, the elevated temperature mechanical properties of service-exposed Cr-Mo-V steel, including creep ductility, high temperature strength, decrease together with the creep cracking resistance. In recent studies, it has been found that the creep exponent $n$ in Norton's law not only depends on stress and temperature, but also relates to creep damage of the material within certain limits. Singh [18] has proved that the $n$ value of virgin $1 \mathrm{Cr} 1 \mathrm{Mo} 1 / 4 \mathrm{~V}$ forged rotor steel is 7.6 , and then it becomes 6.6 after aging treatment at $600^{\circ} \mathrm{C}$ for 3648 hours, which is equivalent to the service exposed condition of 200000 hours at $540^{\circ} \mathrm{C}$. The $n$ values of new and old P92 steel also show the same change trend. In the study reported by Sklenicka [19], $n$ values were found to be 16.3 and 12.8 for new and old P92 steel respectively. Since the index $\Phi_{0}$ of the CCG prediction formula in Eq. (3) depends on the $n$ value according to Eq. (5), reduction in Norton creep exponent $n$ indicates that $\Phi_{0}$ has to change correspondingly for aging material.

\subsection{CCG model for influence of creep damage}

Creep damage promotes creep crack propagation in elevated temperature equipment. To evaluate the residual CCG life of in-service HP-IP rotors more accurately, the creep damage factor should be integrated into the CCG rate-predicting model. Continuum damage mechanics has been associated with high temperature fracture mechanics by some scholars [20, 21]. The model proposed by Webster is adopted in this paper, as shown in Eq. (6). In Webster's model, creep damage accumulates to produce creep crack growth in the process zone at a crack tip, and cause less ductility to be available in the uncracked ligament region. The amount of damage is determined from the strain fraction or life fraction rules. The CCG property degradation induced by creep damage is reflected as the coefficient of 1/(1- $\omega$ ) in Webster's model. For service-exposed steel, creep damage is accumulated from the very beginning of creep and evolves in nonlinear form; CCG performance degrades before the creep process zone is reached. The index $\Phi_{0}$ in Webster's model is determined by the $n$ value, which has a relationship with creep damage. As discussed above, Webster's model is not adequate to predict the fracture life of components that have been operating for a long time. More precise CCG rates can be acquired by replacing the constant exponent $\Phi_{0}$ with a creep-damage-related variable $\Phi(\omega)$ based on Webster's model.

$$
\frac{d a}{d t}=\frac{M_{0}}{1-\omega} \cdot\left(C^{\star}\right)^{\phi}
$$

To explore the relationship between $\Phi$ and $\omega$, the association of $n$ with $\omega$ is necessary. Uniaxial tensile creep tests were carried out on 30Cr1Mo1V steel under constant stress levels of $150 \mathrm{MPa}, 200 \mathrm{MPa}, 220 \mathrm{MPa}, 260 \mathrm{MPa}$ and $280 \mathrm{MPa}$ at $538^{\circ} \mathrm{C}$. The Norton law creep index $n$ values are obtained from the plot of stress versus minimum creep rate, as shown in Figure 4. It is found that values of $n$ decrease with cumulative damage to the serviceexposed steel. Consulting the conclusions of related research, the creep rate increases nonlinearly with increasing creep damage. An expression such as Eq. (7) is assumed to describe the decreasing rule of $n$ over $\omega$ value.

$$
n=\frac{n_{0}}{\exp (\omega)}
$$

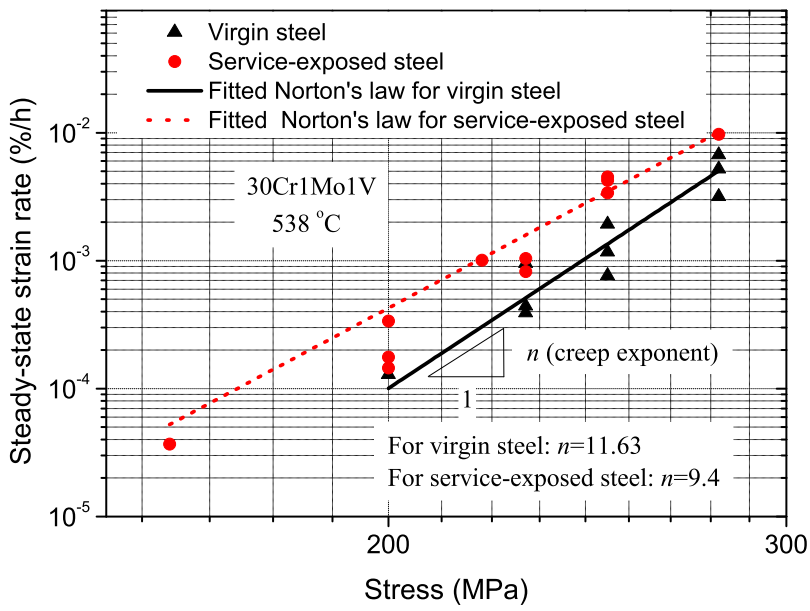

Figure 4: Fitted values of creep index ' $n$ ' for virgin and serviceexposed $30 \mathrm{Cr} 1 \mathrm{Mo} 1 \mathrm{~V}$ steel at $538^{\circ} \mathrm{C}$

The relationship between $\phi$ and damage $\omega$ may be deduced from Eq. (5) and Eq. (7):

$$
\phi=\frac{\phi_{0}}{\phi_{0}-\phi_{0} \cdot \exp (\omega)+\exp (\omega)}
$$

where parameters $\phi_{0}$ and $\phi$ are the material constants of virgin and service-exposed steel, and the $\phi_{0}$ value given in Table 1 is determined from a CCG experiment using virgin steel. 
By replacing $\phi_{0}$ with $\phi$, a modified Webster model is derived in Eq. (9).

$$
\frac{d a}{d t}=\frac{M_{0}}{1-\omega} \cdot\left(C^{\star}\right)^{\phi_{0} /\left[\phi_{0}-\phi_{0} \cdot \exp (\omega)+\exp (\omega)\right]}
$$

For virgin steel, $\omega=0$; in this case the improved Webster model reduces to the classical CCG model.

\subsubsection{Creep damage identification result}

The feasibility of an improved Webster model can be validated by CCG test data for service-exposed steel. The initial creep damage value of service-exposed steel should be identified for the verification. A lot of methodologies [22, 23] have been proposed to compute the creep damage degree of aging material because creep damage is difficult be obtain accurately because of its complexity and detection difficulty. In this paper, creep ductility is employed to calculate the creep damage value; creep ductility can be derived from creep strain, which is more is convenient to measure. The NSW model is a representative model based on the creep ductility method, and it has been widely applied in the finite element analysis of creep crack growth by Zhao [24], Pettina [25] and many other scholars. Assuming that the creep ductility of material with the same creep damage degree is approximately consistent, creep damage of the service-exposed steel can be calculated using the difference of creep ductility between virgin and service-exposed steel. The calculation formula is shown in Eq. (10). In the present paper, the creep ductility of virgin and service-exposed Cr-Mo-V steel is measured from the creep test conducted under constant applied stress of $230 \mathrm{MPa}$ at $538^{\circ} \mathrm{C}$. Table 1 presents the values of steady state creep rate and the corresponding fracture life, as well as the $\omega$ value calculated with Eq. (10).

$$
\omega=\frac{\int_{0}^{t_{f 0}} \dot{\varepsilon}_{0} d t-\int_{0}^{t_{f d}} \dot{\varepsilon}_{d} d t}{\int_{0}^{t_{f 0}} \dot{\varepsilon}_{0} d t}
$$

where $\omega$ is the creep damage; $\dot{\varepsilon}_{0}$ and $\dot{\varepsilon}_{d}$ are the average creep strain rates of virgin and service-exposed material, and $t_{f 0}$ and $t_{f d}$ are the times to rupture of virgin and service-exposed material.

Table 1: Creep damage of service-exposed 30Cr1Mo1V steel calculated by creep ductility method

\begin{tabular}{ccccc}
\hline $\begin{array}{c}\dot{\varepsilon}_{0} \\
(\mathrm{~mm} / \mathrm{h})\end{array}$ & $\begin{array}{c}\dot{\varepsilon}_{d} \\
(\mathrm{~mm} / \mathrm{h})\end{array}$ & $\begin{array}{c}t_{f_{0}} \\
(\mathrm{~h})\end{array}$ & $\begin{array}{c}t_{f_{d}} \\
(\mathrm{~h})\end{array}$ & $\omega$ \\
\hline $7.86 \times 10^{-4}$ & $3.91 \times 10^{-3}$ & 7634 & 1010 & 0.34 \\
\hline
\end{tabular}

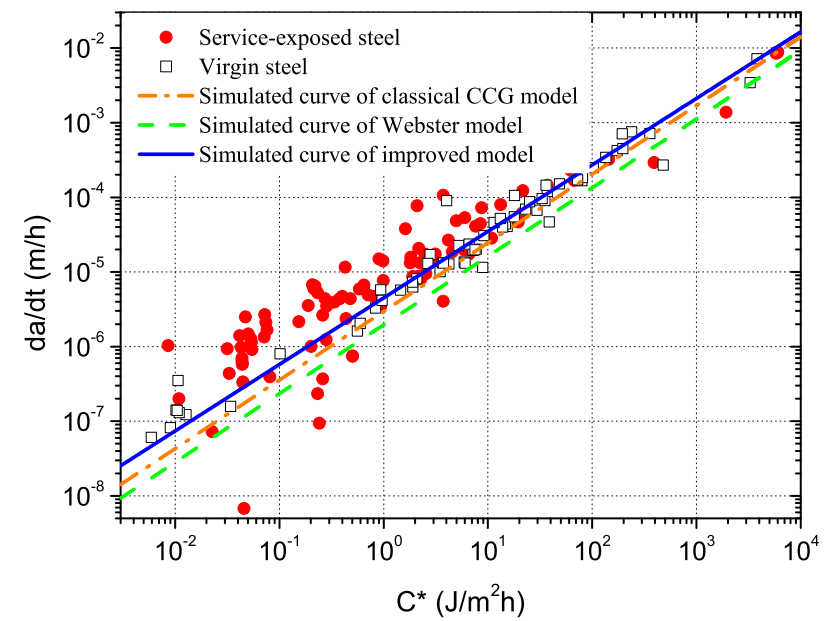

Figure 5: CCG rate (da/dt) as a function of $C^{\star}$ for service-exposure and virgin 30Cr1Mo1V steel

Table 2: Basic parameters of CCG models fitted from virgin 30Cr1Mo1V steel

\begin{tabular}{lll}
\hline $\begin{array}{l}\text { Stress } \\
\text { exponent }\end{array}$ & \multicolumn{2}{l}{ Parameters of CCG models } \\
\hline$n_{0}$ & $M_{0}$ & $\phi_{0}$ \\
11.63 & $2.96 \times 10^{-6}$ & 0.92 \\
\hline
\end{tabular}

\subsubsection{Reliability evaluation of the improved model}

CCG test data of virgin and service-exposed steel at all loading conditions are plotted together in Figure 5. All the test data fall inside a scatter band of $\pm 20 \%$. Observing the scatter plot of CCG rates closely, it is found that the data points of service-exposed steel lie in the upper region of the scatter band, which indicates a faster CCG rate than for the virgin steel. The maximum difference of $\mathrm{d} a / \mathrm{d} t$ between virgin and service-exposed steel was about a factor of 3 for a given value of $C^{\star}$.

The $\log$-log plots of creep crack growth rate against $C^{\star}$ exhibit straight lines during most CCG life. It is apparent that each CCG curve exhibits a 'tail' in the incubation period prior to the steady-state growth for both the virgin and service-exposed steel. Three models are tested to predict the CCG rate of service-exposed steel including: classical CCG model (Eq. (3)), Webster model (Eq. (6)) and the improved Webster model (Eq. (9)). The basic parameters $M_{0}$ and $\phi_{0}$ in these models were obtained from the experimental data of virgin steel, as presented in Table 2. The simulated curves of these 3 models are compared with each other and they are verified by the experiment result.

As shown in Figure 5, the classical CCG model produces the same CCG curve for service-exposed and virgin steel because the damage factor is not contained in Eq. 
(3). The simulated curve of the classical CCG model fits the experimental result of virgin steel well, but a lower simulated accuracy is noted for the service-exposed steel. An overestimate of the remaining CCG life may be speculated from the classical CCG model. The Webster model takes creep damage into account, and the predicted CCG rate becomes faster. However, the constant exponent $\phi_{0}$ in Webster's model makes the simulated curves of serviceexposed steel parallel to the virgin steel, which contradicts the fact that the difference of CCG rates between new and old 30Cr1Mo1V steel get larger with decreased $C^{\star}$ value. This drawback is modified by replacing constant $\phi_{0}$ with a damage effective variable $\phi$ in the improved Webster model. The modification reflects the aging effect on the creep cracking performance. As seen in Figure 5, the slope of the improved Webster model is slightly lower than for the (original) Webster model, and the former's simulated curve is closer to the experimental data for serviceexposed steel. Comparison results validate that the improved Webster model contributes to the accuracy of these calculations.

\section{Conclusions}

This paper presents CCG responses to creep damage for 30Cr1Mo1V rotor steel, and proposes a creep-damagebased CCG model. Creep crack growth experiments are carried out on virgin and service-exposed rotor steel for comparison. Creep crack nucleation and growth rates of service-exposed steel are accelerated by creep damage due to metallurgical variations. The difference of CCG resistance between virgin and service-exposed steel become greater with creep damage accumulation and the decrement of $C^{\star}$ value.

The CCG model derived by Webster is improved by substituting the constant exponent $\phi_{0}$ with a creepdamage-related exponent parameter $\phi . \phi$ is derived from the hypothetical relationship between creep damage $\omega$ and creep index $n$ obtained from creep experiments of rotor steel. The improved Webster model is validated against the CCG test data of the studied service-exposed 30Cr1Mo1V steel, and compared to the classical CCG model and Webster model. The creep damage value used in the validation is identified with the creep ductility method. The compared results show that the improved Webster model contributes to a more accurate description of the CCG behavior of service-exposed rotor steel.

\section{References}

[1] Zhao C.Z., Wei S.S., Gao Y.L., Wang Y.H., Progress of HeatResistant Steel for Supercritical and Ultra-Supercritical Steam Turbine, J IRON STEEL RES INT., 2007, 19, 1-5.(in Chinese)

[2] Mazza E., Holdsworth S.R., Skelton R.P., Characterisation of the creep-fatigue behavior of a $1 \mathrm{CrMoV}$ turbine steel, Mater. High Temp., 2004, 21, 119-128.

[3] Sugiura R., Yokobori A.T. Jr., Tabuchi M., Yokobori T., Comparison of creep crack growth rate in heat affected zone of welded joint for $9 \% \mathrm{Cr}$ ferritic heat resistant steel based on $\mathrm{C}^{\star}, \mathrm{d} \delta / \mathrm{dt}, \mathrm{K}$ and $Q^{\star}$ parameters, Eng Fract Mech., 2007, 74, 868-881.

[4] Kwon O., Thomas C.W., Knowles D., Multiaxial stress rupture behaviour and stress-state sensitivity of creep damage distribution in Durehete 1055 and 2.25 Cr1Mo steel, Int J Pres Ves Pip., 2004, 81, 535-542.

[5] Webster G.A., Ainsworth R.A., High temperature component life assessment. Chapman \& Hall Press, London, 1994.

[6] Andersson H., Sandström R., Creep crack growth in serviceexposed weld metal of 2.25 Cr1Mo, Int J Pres Ves Pip., 2001, 78, 749-755.

[7] Nikbin K., Smith D., Webster G., Prediction of creep crack growth from uniaxial creep data, P ROY SOC A-MATH PHY., 1984, 396, 183-197.

[8] Murakami S., Liu Y., Mizuno M., Computational methods for creep fracture analysis by damage mechanics, Comput Method Appl., 2000, 183, 15-33.

[9] Kachanov M., On the concept of damage in creep and in the brittle-elastic range, Int J Damage Mech., 1994, 3, 329.

[10] Webster G.A., 5.05-Creep Crack Growth, in: Milne I., Ritchie R.O., Karihaloo B. (Eds.), Comprehensive Structural Integrity, Elsevier Ltd., 2003, 241-271.

[11] ASTM, ASTM E1457-07, Standard Test Method for Measurement of Creep Crack Growth Rates in Metals, ASTM International. 2007

[12] Dobrzański J., Internal damage processes in low alloy chromium-molybdenum steels during high-temperature creep service, J Mater Process Tech., 2004, 157, 297-303.

[13] Joarder A., Sarma D., Cheruvu N., Effect of long-term service exposure on microstructure and mechanical properties of a CrMoV steam turbine rotor steel, Metall Mater Trans A., 1991, 22, 18111820.

[14] Cheruvu N., Degradation of mechanical properties of $\mathrm{Cr}-\mathrm{Mo}-\mathrm{V}$ and 2.25 Cr-1Mo steel components after long-term service at elevated temperatures, Metall Mater Trans A., 1989, 20, 87-97.

[15] Abe F., Stress to produce a minimum creep rate of $10-5 \% / h$ and stress to cause rupture at $105 / \mathrm{h}$ for ferritic and austenitic steels and superalloys, Int J Pres Ves Pip., 2008, 85, 99-107.

[16] Ennis P., Zielinska-Lipiec A., Wachter O., Czyrska-Filemonowicz A., Microstructural stability and creep rupture strength of the martensitic steel P92 for advanced power plant, Acta Mater., 1997, 45, 4901-4907.

[17] Sklenička V., et al., Long-term creep behavior of 9-12\% $\mathrm{Cr}$ power plant steels, MATER CHARACT., 2003, 51, 35-48.

[18] Singh K., Kamaraj M., Microstructural Degradation in Power Plant Steels and Life Assessment of Power Plant Components, Procedia Engineering., 2013, 55, 394-401.

[19] Sklenička V., et al., The effect of hot bending and thermal ageing on creep and microstructure evolution in thick-walled P92 steel 
pipe, Mat Sci Eng A-Struct., 2015, 644, 297-309.

[20] Lemaitre J., A continuous damage mechanics model for ductile fracture, J ENG MATER-T ASME., 1985, 107, 83-89.

[21] Hayhurst D., Hayhurst R., Vakili-Tahami F., Continuum damage mechanics predictions of creep damage initiation and growth in ferritic steel weldments in a medium bore branched pipe under constant pressure at $590^{\circ} \mathrm{C}$ using a five-material weld model, P Roy Soc A-Math Phy., 2005, 461, 2303-2326.

[22] Dewasurendra M., Vajravelu K., On the method of inverse mapping for solutions of coupled systems of nonlinear dierential equations arising in nanofluid flow, Heat and Mass Transfer, Applied Mathematics and Nonlinear Sciences. 2018, 3, 1-14.
[23] Khellat F., Khormizi M.B., A global solution for a reactiondiusion equation on bounded domains, Applied Mathematics and Nonlinear Sciences. 2018, 3, 15-22.

[24] Zhao L., Jing H.Y., Han Y.D., Xiu J.J., Xu L.Y., Prediction of creep crack growth behavior in ASME P92 steel welded joint, Comp Mater Sci., 2012, 61, 185-193.

[25] Pettina M., Biglari F., Heaton A., Brown P., Nikbin K., Modelling damage and creep crack growth in structuralceramics at ultrahigh temperatures, J Eur Ceram Soc., 2014, 34, 2799-2805. 